\title{
Ontogeny of the Epidermal Barrier to Water Loss in the Rat: Correlation of Function with Stratum Corneum Structure and Lipid Content
}

\author{
MICHELLE ASZTERBAUM, GOPINATHAN K. MENON, KENNETH R. FEINGOLD, AND \\ MARY L. WILLIAMS \\ Departments of Dermatology, Medicine and Pediatrics, University of California, San Francisco and the \\ Dermatology and Medical Services, Veterans Administration Medical Center, San Francisco. California 94121
}

\begin{abstract}
The mammalian epidermal permeability barrier is provided by highly hydrophobic lipids forming multiple membrane bilayers within the extracellular domains of the outer, cornified cell layers. To characterize the critical events associated with barrier maturation, we correlated the emergence of a competent barrier to transepidermal water loss with development of the lamellar body secretory system, the organization of stratum corneum membrane bilayers, and the lipid composition of these membranes in the perinatal rat. Whereas pups of $19 \mathrm{~d}$ estimated gestational age had no measurable barrier (transepidermal water loss $>10 \mathrm{mg} / \mathrm{cm}^{2} / \mathrm{h}$ ), by $21 \mathrm{~d}$ the barrier was well established (mean transepidermal water loss 0.41 $\mathrm{mg} / \mathrm{cm}^{2} / \mathrm{h}$ ). Development of a functional barrier correlated with increasing thickness of the stratum corneum, as well as with development of a membrane pattern of lipid deposition, visualized with the hydrophobic fluorescent probe nile red. At 19 d estimated gestational age, the stratum corneum intercellular domains exhibited an abundance of secreted lamellar body contents, but they were not organized into basic bilayer unit structures. Lamellar unit structures became evident by $20 \mathrm{~d}$ and extended throughout the stratum corneum interstices by $22 \mathrm{~d}$ (term). The quantity of lipid in isolated stratum corneum increased significantly between 19 and $20 \mathrm{~d}(34.08$ versus 50.08 mean $\mu \mathrm{g}$ lipid/ $\mathrm{cm}^{2}$, respectively; $\left.p<0.02\right)$ and still further between 20 and $21 \mathrm{~d}$ estimated gestational age $\left(74.49 \mu \mathrm{g} \mathrm{lipid} / \mathrm{cm}^{2} ; p\right.$ $<0.001)$. This increase was due to progressive accumulation of neutral lipids, particularly cholesterol, as well as nonpolar ceramides, as shown by thin-layer chromatography/scanning densitometry. These studies imply that in the development of cutaneous barrier function in the fetal rat both the generation of sufficient quantities of hydrophobic lipids and the organization of these lipids into bilayer unit structures are required. (Pediatr Res 31: 308-317, 1992)
\end{abstract}

\section{Abbreviations}

TEWL, transepidermal water loss EGA, estimated gestational age TLC, thin-layer chromatography

The primary function of mammalian epidermis during terrestrial life is the generation and maintenance of a competent barrier

Received October 11, 1991; accepted December 4, 1991

Correspondence and reprint requests: Mary L. Williams, M.D., Dermatology Service (190), Veterans Administration Medical Center, 4150 Clement St., San Francisco CA 94121.

Supported in part by NIH Grants AR 39639 and AR 29908 and the Medical Research Service, Veterans Administration. to TEWL. Although the term human neonate is born with a competent barrier $(1-3)$, preterm infants $(<33 \mathrm{wk}$ EGA) have an impaired barrier to both water loss and the percutaneous absorption of water-soluble compounds; the extent of barrier dysfunction is proportional to the degree of prematurity (3-8). TEWL accounts for $75 \%$ of the insensible water loss in the preterm infant and may lead to dehydration and thermoinstability (9-15). Despite its clinical importance, there has been relatively little research into the physiologic, structural, or chemical basis for barrier immaturity. Evans and Rutter (16) have noted that a well-formed stratum corneum is found in infants only after 34 wk EGA, a finding that correlates with a competent barrier after this time.

It is widely recognized that in mammalian epidermis the permeability barrier resides within the stratum corneum. Moreover, it is not the keratins or other structural proteins that fill and surround the cornified cells that constitute the barrier. Instead, the barrier resides in the stratum corneum's complement of highly hydrophobic lipids, arranged in the form of multiple membrane bilayers between the cornified cells (reviewed in Ref. 17). Ultrastructurally, these intercellular bilayers exhibit a characteristic pattern of repeating electron-lucent (hydrophobic) and electron-dense (hydrophilic) lamellae (18-20), which has been termed the basic lamellar bilayer unit (20)

These membrane bilayers derive from a secretory organelle, the epidermal lamellar body (21). Lamellar bodies are enriched in phospholipids, free sterols, glucosylceramides, and a selected complement of hydrolytic enzymes, including lipases, glycosidases, and proteases (22-25). Upon secretion of lamellar body contents at the stratum granulosum/stratum corneum interface, these enzymes apparently convert the polar lipids and glycosphingolipids to neutral lipids and ceramides. In mature mammalian skin, lipids compose $5-10 \%$ of stratum corneum weight and are composed predominantly of free sterols, FFA, and ceramides (26-31). The ceramides contain a high proportion of saturated, very long chain fatty acids $(28,30-37)$, which presumably contribute to the hydrophobic properties of stratum corneum membranes. One class of ceramides unique to epidermis, the so-called acylceramides, has been particularly implicated in barrier function (37); this species contains linoleic acid (C18:2) esterified to the $\omega$-terminus of a very long chain (C30-C34), nacyl $\alpha$-hydroxy fatty acid.

Despite the known importance of stratum corneum lipids for barrier function, little information exists about the lipid content and bilayer organization in relation to maturation of the permeability barrier in man or other mammals. In view of the difficulty in obtaining human material, these studies were undertaken to determine if the perinatal rat could provide a suitable model system to study the ontogenesis of the permeability barrier. In the studies reported here, we delineate the time course for the establishment of a competent barrier to water loss in rats between 
19 and $22 \mathrm{~d}$ EGA and correlate these data with the content and structural organization of lipids in the stratum corneum.

\section{MATERIALS AND METHODS}

Materials. Timed-pregnant primiparous Sprague-Dawley rats (6-10 wk old) were purchased from Simonsen Laboratories (Gilroy, CA) and were fed Purina Laboratory Chow 5001 (Ralston-Purina Co., St. Louis, MO) and water ad libitum. The plug date was taken as $\mathrm{d} 0$, and spontaneous delivery occurred at $\mathrm{d}$ $22(n=7)$. Ruthenium tetroxide and nile red were obtained from Polysciences, Inc. (Warrington, PA). OCT compound for embedding was obtained from Miles Scientific (Naperville, IL). EDTA and bovine pancreatic trypsin were purchased from Sigma Chemical Co. (St. Louis, MO). Authentic lipid standards were purchased from Sigma Chemical Co., and Avant was purchased from Polar Lipids, Inc. (Pelham, AL). High-performance silica gel TLC plates were purchased from Merck (Darmstadt, Germany).

Transepidermal water loss. Premature rat pups were obtained by cesarean section using isofluorane or halothane anesthesia at $18,19,20,21$, and 22 (term) d EGA. Neonates were patted dry immediately after delivery and floated with their placental connections intact on a raft in a $36^{\circ} \mathrm{C}$ water bath. TEWL was measured from the interscapular dorsal region using a $0.5-\mathrm{cm}^{2}$ probe of a Meeco electrolytic moisture analyzer (Warrington, PA $(38,39)$. All TEWL measurements were obtained within $1 \mathrm{~h}$ of delivery. Data were expressed as $\mathrm{mg} \mathrm{H}_{2} \mathrm{O} / \mathrm{cm}^{2} / \mathrm{h}$ as described (40) and expressed as mean $\pm \mathrm{SD}$.

Stratum corneum isolation and lipid extraction. After measurement of TEWL, the umbilical cord was ligated and the pups were weighed. Pups were then killed by cervical dislocation, and skin between the midaxillary lines, posterior neck, and rump was excised. An intact sheet of epidermis was obtained by floating whole skin, dermis side down, in 20 mM EDTA in Dulbecco's PBS in a $37^{\circ} \mathrm{C}$ water bath for $40 \mathrm{~min}$. The surface area of the epidermal sheet was determined by tracing its perimeter onto a transparent Petri dish and transferring that image to Whatman filter paper. Tracings were cut out and weighed, and the area of the original epidermal sheet was calculated by reference to a standard curve of filter paper weight versus area. To isolate the stratum corneum, the epidermal sheet was floated basal side down in Hanks' balanced salt solution supplemented with $0.1 \%$ trypsin and $50 \mathrm{mM}$ sodium phosphate $(\mathrm{pH} 7.4)$ overnight at $4^{\circ} \mathrm{C}$. Detached cells were then irrigated away; paraffin-embedded sections of isolated sheets demonstrated only cornified cells. Lipids were then extracted from the stratum corneum sheets (41), dried under nitrogen, and redissolved in chloroform, and an aliquot was weighed on a Cahn 21 electrobalance (Cahn Instruments, Inc., Cerritos, CA).

TLC. Stratum corneum lipids from two fetal rats of each gestational group were fractionated and quantitated by highperformance TLC followed by charring and scanning densitometry, using a modification of the method described by Ponec et al. (42). Lipid (4 to $20 \mu \mathrm{g}$ ) was solubilized in chloroform and applied in 5-mm lanes using a CAMAG Linomat IV autospotter (CAMAG Scientific, Inc., Wrightsville Beach, NC) onto $10 \mathrm{~cm}$ $\times 20 \mathrm{~cm}$ TLC plates. Five lanes of authentic standards in quantities between 0.2 and $1.0 \mu \mathrm{g}$ were applied at either end of the plate to establish standard curves. Plates were developed at $4^{\circ} \mathrm{C}$ using a CAMAG horizontal developing system. Neutral lipids were developed to $40 \mathrm{~mm}, 60 \mathrm{~mm}$, and $80 \mathrm{~mm}$ in petroleum ether:diethylether:acetic acid (80:20:1 vol/vol/vol) (Fig. 1). The fraction that migrates just below cholesterol is provisionally assigned to 7-dehydrocholesterol (Fig. 1, asterisk), based upon comigration with authentic standard (data not shown) and the previous identification of this sterol in rat skin $(43,44)$. Sphingolipids were subfractionated by sequential development in three solvent systems; system 1, chloroform:methanol:acetone (76:20:4 $\mathrm{vol} / \mathrm{vol} / \mathrm{vol})$, developed first to $10 \mathrm{~mm}$, then $35 \mathrm{~mm}$; system 2 ,

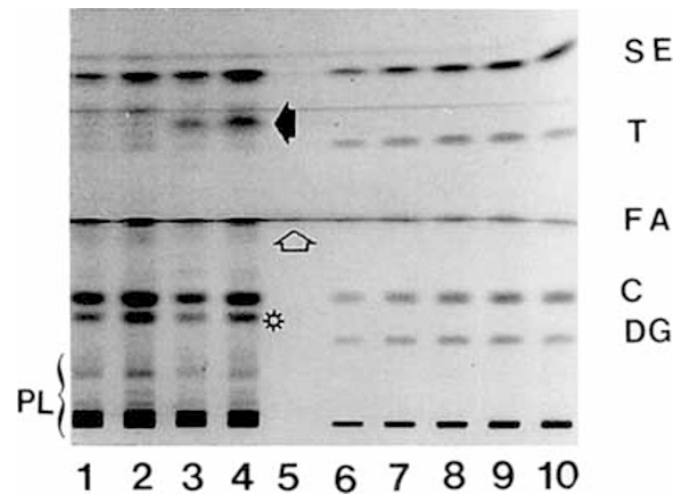

Fig. 1. Representative thin-layer chromatogram of fetal rat stratum corneum lipids developed for resolution of neutral lipids. Photograph of portion of TLC plate illustrating neutral lipid development. Right five lanes represent neutral lipid standards (lanes 6-10:0.2, 0.4, 0.6,0.8, and $1.0 \mu \mathrm{g}$ of each authentic standard, respectively): and left four lanes represent 4- $\mu \mathrm{g}$ (lanes 1 and 3 ) and 8- $\mu \mathrm{g}$ (lanes 2 and 4 ) applications of fetal rat stratum corneum lipids (lanes 1 and 2: $21 \mathrm{~d} \mathrm{EGA;} \mathrm{lanes} 3$ and 4: 22 d EGA). SE, sterol esters; $T$, triacylglycol; $F A$, fatty acids; $C$, cholesterol; and $D G, 1,2$-diacylglycerol. Brace indicates sphingolipid/ polar lipid $(P L)$ region. Asterisk indicates 7-dehydrocholesterol. Open arrow indicates solvent contaminant comigrating with FA standard in blank lane 5. Solid arrow indicates unknown fraction that is more prominent in term (22-d) pups (lanes 3 and 4).

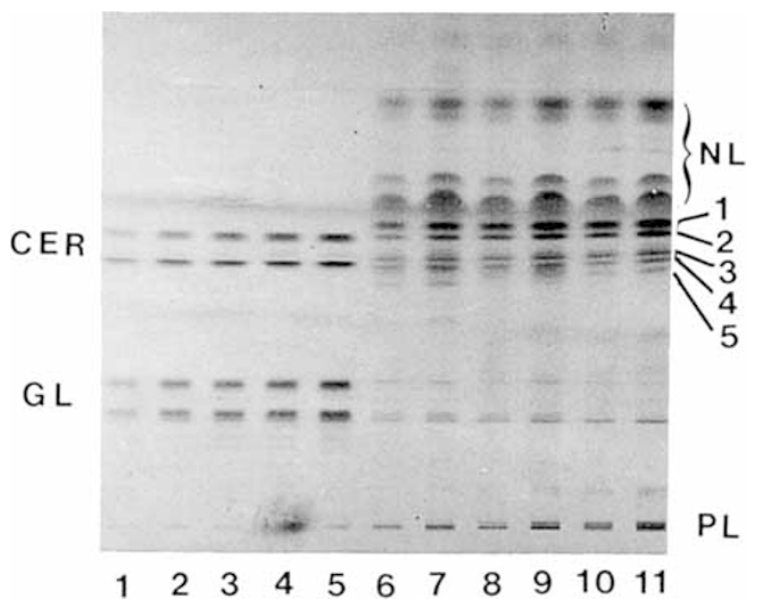

Fig. 2. Representative thin-layer chromatography of fetal rat stratum corneum lipids developed for resolution of sphingolipids. Photograph of portion of TLC plate illustrating sphingolipid development. Left five lanes represent sphingolipid standards (lanes $1-5: 0.2,0.4,0.6,0.8$, and $1.0 \mu \mathrm{g}$ of each authentic standard, respectively), and right six lanes represent developments of $10 \mu \mathrm{g}$ (lanes 6, 8, and 10) and $20 \mu \mathrm{g}$ (lanes 7 , 9 , and 11 ) of fetal rat stratum corneum lipids (lanes 6 and 7: $19 \mathrm{~d}$ EGA; lanes 8 and 9: $20 \mathrm{~d}$ EGA; lanes 9 and 10:21 d EGA). Ceramides are designated $1-5$ in order of increasing polarity. $N L$, Neutral lipids; GL, glycosphingolipids; and $P L$, polar lipids.

chloroform:acetone:methanol $(80: 10: 10 \mathrm{vol} / \mathrm{vol} / \mathrm{vol})$ to $75 \mathrm{~mm}$; and system 3, chloroform:ethylacetate:diethylether:methanol (76:20:6:2 vol/ $\mathrm{vol} / \mathrm{vol} / \mathrm{vol}$ ) to the top (Fig. 2). Ceramide fractions were designated 1 to 5 in order of increasing polarity (decreasing rate of flow) (Fig. 2). Phospholipids were subfractionated by sequential development in three different solvent mixes: system 1, chloroform: ethylacetate:ethylmethylketone:2-propanol: ethanol:methanol:acetic acid:hexylacetate $(34: 4: 4: 6: 20: 28: 4: 1)$ to $36 \mathrm{~mm}$, then to $52 \mathrm{~mm}$; system 2 , chloroform:ethylacetate:ethylmethylketone:2-propanol:ethanol:methanol:water (46:4:4:6:6:28:6) to $66 \mathrm{~mm}$; and system 3 , chloroform:diethylether:ethylacetate:methanol $(76: 6: 20: 2 \mathrm{vol} / \mathrm{vol} / \mathrm{vol} / \mathrm{vol})$ to 100 $\mathrm{mm}$. After development, TLC plates were dried for $5 \mathrm{~min}$, then 
vertically dipped for $15 \mathrm{~s}$ into a charring solution composed of $1.5 \%$ hydrated copper sulphate, $5 \%$ glacial acetic acid, $1 \%$ concentrated sulfuric acid, $1 \%$ ortho-phosphoric acid (wt/vol). Plates were dried then transferred to a mechanical convection oven (Proset II; Blue M, Blue Island, IL) and charred at $180^{\circ} \mathrm{C}$ for 15 min. Cooled plates were scanned using a recording photo-densitometer equipped for automatic peak integration (CAMAG TLC Scanner II). Lipids were quantitated in reference to commercially obtained authentic standards. Ceramide fractions were quantitated in reference to the closest migrating ceramide standard. Because of a solvent contaminant that comigrates with FFA (Fig. 1 ), the density of this contaminant in a blank central lane was subtracted from the density of the fatty acid region in standards and samples. Data are expressed as the change in the mean $\mu \mathrm{g}$ lipid $/ \mathrm{cm}^{2}$ stratum corneum \pm SEM between $19 \mathrm{~d}$ versus older fetal material.

Light and electron microscopy. Skin was obtained for light microscopy within 15 min of delivery, embedded in OCT compound, and stored at $-70^{\circ} \mathrm{C}$. Samples were sectioned to $4-6 \mu \mathrm{m}$ using a Tissue-Tek (Miles Scientific) RII cryostat, nile red (100 $\mu \mathrm{g} / \mathrm{mL}, 75 \%$ glycerol) was applied (45), and sections were examined with a Nikon Microphot-FX microscope (Nikon Inc., Garden City, NY) equipped with epifluorescence (excitation of $470-490 \mathrm{~nm}$, emission $520 \mathrm{~nm}$ ).

Skin was obtained for electron microscopy within $4 \mathrm{~min}$ of delivery and was minced and fixed in $2 \%$ glutaraldehyde, $2 \%$ paraformaldehyde with $0.06 \% \mathrm{CaCl}_{2}$ in $0.1 \mathrm{M}$ sodium cacodylate buffer $(\mathrm{pH} \mathrm{7.3)}$ for $1 \mathrm{~h}$ at room temperature and overnight at $4^{\circ} \mathrm{C}$. Samples were then washed in $0.1 \mathrm{M}$ sodium cacodylate buffer and $5 \%$ sucrose for $24 \mathrm{~h}$ at $4^{\circ} \mathrm{C}$ and postfixed in either $0.2 \%$ ruthenium tetroxide or $2 \%$ reduced osmium tetroxide (20). Tissue samples were dehydrated in a graded ethanol series and subsequently embedded in an epon-epoxy mixture (46). Thick $(0.5 \mu \mathrm{m})$ sections on glass slides were stained with toluidine blue. Thin sections were double-stained with lead citrate and uranyl acetate (osmium tetroxide-fixed specimens) or with lead citrate alone (ruthenium tetroxide-fixed samples). Thin sections were examined in a Zeiss $10 \mathrm{~A}$ electron microscope operating at 60 $\mathrm{kV}$.

Statistical analysis. For statistical purposes, data from animals of different gestational ages were compared using the $t$ test.

\section{RESULTS}

TEWL. To examine the time course of barrier development, TEWL was measured in rat pups delivered at 18,19,20,21, and 22 d EGA (Fig. 3). TEWL was also measured on pups spontaneously delivered at $22 \mathrm{~d}$ EGA, as well as $1 \mathrm{~d}$ after birth. No measurable barrier was evident in pups of either 18 or $19 \mathrm{~d}$ EGA $(n=41)$, i.e. all displayed TEWL measurements surpassing the maximal detectable rates $\left(>10 \mathrm{mg} / \mathrm{cm}^{2} / \mathrm{h}\right)$. Pups of $20 \mathrm{~d}$ EGA showed varying degrees of barrier function; whereas some pups exhibited no measurable barrier function (four of 52), others exhibited a highly competent barrier, i.e. TEWL as low as 0.125 $\mathrm{mg} / \mathrm{cm}^{2} / \mathrm{h}$ (range shown in Fig. 3) (TEWL $1.77 \mathrm{mg} \pm 0.36 / \mathrm{cm}^{2} /$ $\mathrm{h}$, mean \pm SEM). By $21(n=23)$ and $22(n=23) \mathrm{d}$ EGA, all pups displayed a competent barrier; TEWL was $0.41 \pm 0.04$ and $0.14 \pm 0.02 \mathrm{mg} / \mathrm{cm}^{2} / \mathrm{h}$, mean \pm SEM, respectively. The differences in TEWL between $\mathrm{d} 20$ and $\mathrm{d} 21$ and between $\mathrm{d} 21$ and $\mathrm{d}$ 22 were each highly significant $(p<0.001)$. TEWL in 22-d EGA pups delivered by cesarean section was comparable to TEWL in those born spontaneously (data not shown). One-d postbirth neonates $(n=10)$ exhibited a further, modest improvement in barrier function (TEWL $0.10 \pm 0.01 \mathrm{mg} / \mathrm{cm}^{2} / \mathrm{h}$, mean \pm SEM) $(p<0.05)$ that is comparable to barrier competence in adult rodents (37-39). Development of a competent barrier also correlated with increasing body weight (data not shown). Virtually all pups ( 45 of 46 ) less than $3.0 \mathrm{~g}$ had no measurable barrier to water loss, whereas pups $>4.5 \mathrm{~g}$ body weight had reasonably competent barriers (TEWL $<0.75 \mathrm{mg} / \mathrm{cm}^{2} / \mathrm{h}$ ). Pups of $>6.0 \mathrm{~g}$

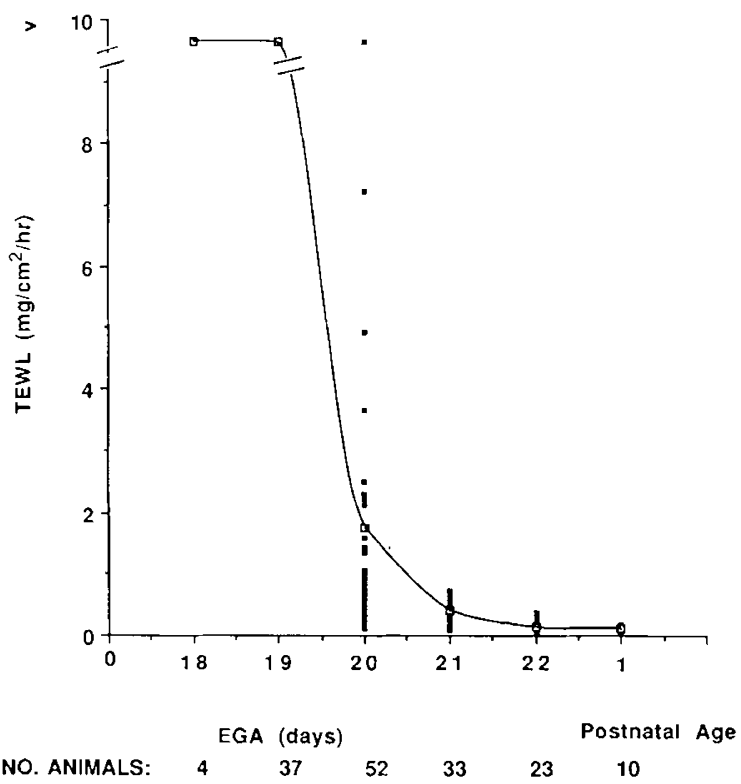

Fig. 3. Transepidermal water loss in relation to gestational age. Rat pups were delivered by cesarean section at $18,19,20,21$, or $22 \mathrm{~d}$ EGA or spontaneously delivered at $22 \mathrm{~d}$, and TEWL was measured. The break in the $y$ axis indicates measurements that were off scale by our instrumentation ( $>10 \mathrm{mg} / \mathrm{cm}^{2} / \mathrm{h}$; see Materials and Methods). Open squares indicate the mean TEWL for each age group. Individual circles demonstrate the range of TEWL observed. Multiple pups having the identical TEWL are shown as a single data point. Pups of 18 and $19 \mathrm{~d}$ EGA have no measurable barrier to water loss, whereas a competent barrier is present in all pups by $21 \mathrm{~d}$ (mean TEWL $0.41 \mathrm{mg} / \mathrm{cm}^{2} / \mathrm{h}$ ).

exhibited barrier function comparable to that of adult rodent skin $(38-40)$. Thus, the establishment of an epidermal barrier to water loss occurs during late gestation of the fetal rat. Indeed, events occurring during the 20 th $\mathrm{d}$ of gestation initiate a partially effective barrier, with further increments in barrier competence elaborated during subsequent gestation and postgestational development.

Light microscopy. To assess the morphologic changes that accompany the development of a competent permeability barrier, resin-embedded sections of fetal rat skin stained with toluidine blue were examined (Fig. 4A-C). Epidermis from 19-d EGA pups, who displayed no measurable barrier, exhibited a prominent, darkly staining peridermal layer (Fig. 4A, open arrow). Although the outermost one or two epidermal layers appeared to be anucleate (solid arrow), a well-defined stratum corneum was not seen. The epidermis of $20 \mathrm{~d}$ EGA pups (the time during which barrier competence is first established) was thicker, and keratohyalin granules (solid arrow) were prominent within the upper nucleated cell layers (Fig. $4 B$ ). Moreover, a well-delineated stratum corneum was evident, with remnants of the periderm still present (Fig. $4 B$ ). In term pups ( $22 \mathrm{~d}$ EGA), further increments in epidermal and stratum corneum thickness were evident (Fig. $4 C$ ). These results show that the development of barrier competence after $20 \mathrm{~d}$ EGA correlated with increasing epidermal and stratum corneum thickness.

Histochemistry. To ascertain the pattern of distribution of polar versus nonpolar lipids in the epidermis, frozen sections of skin stained with the lipid probe nile red were examined by fluorescence microscopy (Fig. $5 A-D$ ). This probe changes its staining properties relative to the polarity of the lipid environment, i.e. it fluoresces yellow-gold when nonpolar lipids are present and red or red-orange in the presence of lipids less polar than ceramides (45). In adult rodent epidermis, changes in the histochemistry with nile red correlate well with variations in lipid composition among epidermal strata (47). Like adult rodent skin, the nucleated layers of epidermis from term rat pups $22 \mathrm{~d}$ 


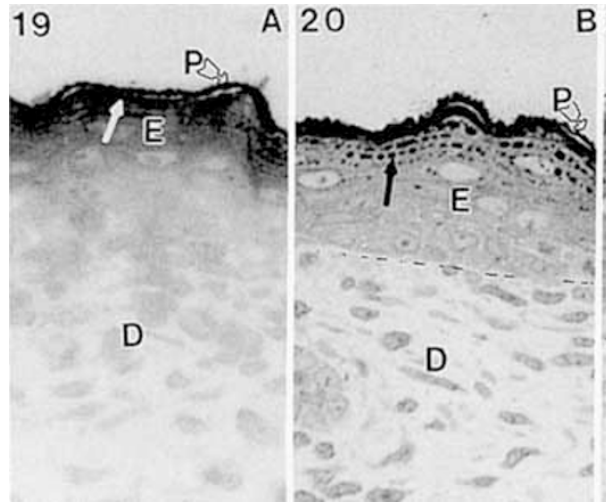
B 21
C 22

D

Fig. 4. Histology of fetal rat skin. In plastic-embedded, $0.5-\mu \mathrm{m}$ sections stained with toluidine blue, a prominent darkly stained periderm layer ( $P$; open arrow) and one or two outer annucleate layers (solid arrow) of epidermis $(E)$ are present in $19 \mathrm{~d}$ EGA pups $($ panel $A)$. By $20 \mathrm{~d}$, the epidermis is thicker, keratohyalin granules (solid arrow) are prominent in the upper nucleated layers, and a well-delineated stratum corneum is evident ( panel B). By $21 \mathrm{~d}$ (panel $C$ ), a multilayered stratum corneum (brackets) is seen, with a remnant of periderm $(P)$ still attached. By term $(22$ d) (panel $D$ ) further increase in thickness of the nucleated epidermal strata and in stratum corneum are evident. Original magnification $\times 500$.
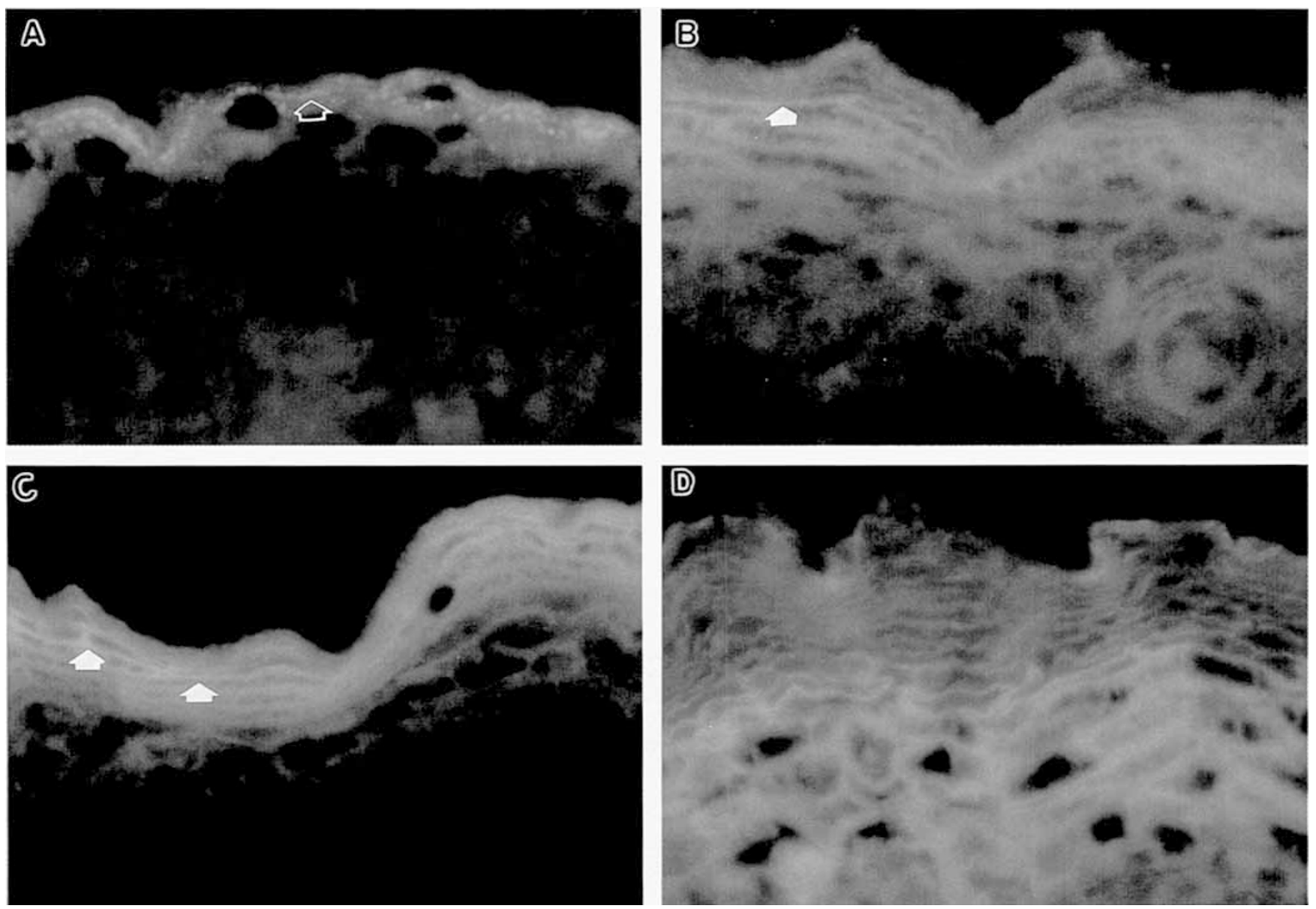

Fig. 5. Lipid histochemistry of fetal rat epidermis. Frozen sections of rat skin were stained with the fluorescent probe nile red. Fluorescence of epidermis of pups of $19 \mathrm{~d}$ EGA ( panel $A$ ) displayed a beaded pattern in the outermost layers (open arrow). By $20 \mathrm{~d}$ (panels $B$ and $C$ ), approximately three layers of yellow-gold membrane pattern staining were evident in the outermost epidermal layers (closed arrows). More intense membrane staining (panel $C$ ) was evident in pups having better barrier function (TEWL 3.6 and $1.0 \mathrm{mg} / \mathrm{cm}^{2} / \mathrm{h}$, panels $B$ and $C$, respectively). By term $(22 \mathrm{~d}$ EGA; panel $D$ ) the mature rodent skin pattern of nile red fluorescence is established; nucleated cell layers fluoresce red-orange in a cytoplasmic pattern, whereas the multilayered stratum corneum fluoresces yellow-gold in a membrane staining pattern. Original magnification $\times 750$.

EGA) showed red, fluorescent staining in a cytosolic pattern, whereas the outermost nucleated layers and the stratum corneum fluoresced yellow-gold in a membrane-staining pattern (Fig. 5D). In contrast, epidermis from pups of $19 \mathrm{~d}$ EGA, with no measurable barrier function, demonstrated orange lipid droplets, often arrayed in a beaded pattern in the outermost epidermal layers
(Fig. $5 A$ ). As noted above, a well-defined stratum corneum is not present at this age, nor did we observe a membrane pattern of fluorescence in the outermost cell layers with nile red (Fig. $5 A$ ). At $20 \mathrm{~d}$ EGA, approximately three layers of yellow-gold membrane-staining pattern were observed in the outermost epidermis (Fig. $5 B$ and $C$ ). Moreover, in those pups of $20 \mathrm{~d}$ EGA, 
in whom a more competent barrier was present, we observed more intense staining of stratum corneum intercellular domains than in those pups with poorer barrier function (e.g. Fig. 5, panel $B$ versus $C$, TEWL 3.6 versus $1.0 \mathrm{mg} / \mathrm{cm}^{2} / \mathrm{h}$, respectively). These studies illustrate that the emergence of a competent barrier in the perinatal rat correlates with establishment of a nonpolar lipid-staining pattern in the membrane domains of the stratum corneum.

Electron microscopy. To examine the ultrastructure of the perinatal rat epidermis, postfixations with both osmium tetroxide and ruthenium tetroxide were used (Figs. 6-8). Whereas the former permits assessment of routine ultrastructural features, including lamellar bodies, ruthenium tetroxide reveals the organization of stratum corneum intercellular membrane bilayers $(18-20)$. In mature stratum corneum, intercellular lamellae are organized as unit structures consisting of alternating electronlucent and electron-dense lamellae (e.g. Fig. 8, upper inset): a single continuous electron-lucent lamella lies external to the cornified cell envelope; between these electron-lucent lamellae lie repeating units formed by pairs of continuous electron-lucent lamellae flanked on either side by interrupted electron-lucent lamellae. One to three such repeating units normally may be found (18-20).

Despite the absence of a well-defined stratum corneum on light microscopy of $19 \mathrm{~d}$ EGA pups (see above), approximately two cell layers, exhibiting the incomplete cornification of transitional cells, were evident below the periderm on electron microscopy (Fig. 6). Although lamellar bodies were numerous within the mid and outer nucleated epidermal cell layers of 19 d EGA pups (Fig. 6, inset), we noted considerable heterogeneity in their architecture; some appeared to be empty (i.e. lacked internal lamellations), whereas others exhibited a mature internal membrane pattern (Fig. 6, inset). Moreover, although abundant lamellar material was present in the intercellular domains of the outermost epidermal cell layers (Fig. 6, double arrows), it formed an irregular pattern of foreshortened lamellae, resembling the pattern of newly secreted lamellar body membrane structures, a pattern that in mature rodent epidermis is confined to the junction of the stratum corneum and stratum granulosum (Fig. 8, lower left inset; 20). The characteristic elongated, lamellar basic unit structures of mature stratum corneum were not found in pups of this age.

By $20 \mathrm{~d}$ EGA, four to five cornified cell layers were evident (Fig. 7). The innermost cornified layers showed secreted lamellar body-derived membrane structures (Fig. 7, upper left inset), whereas the outer layers displayed foci that appeared devoid of intercellular lamellar material (Fig. 7, center). Other areas exhibited the basic lamellar bilayer unit structures described above for mature skin (Fig. 7, upper right inset; compare Fig. 8, upper right inset). In pups of this age, lamellar bodies continued to show heterogeneity, i.e. some were devoid of internal contents, whereas others were well formed (Fig. 7, center). In contrast, by $21 \mathrm{~d}$ EGA (Fig. 7, bottom panel) or term (22 d EGA) (Fig. 8) intercellular spaces of the stratum corneum were completely filled with basic bilayer unit structures. Similarly, nearly all epidermal lamellar bodies at term exhibited well-formed internal membrane ultrastructure (Fig. 8, lower right inset).

Thus, the emergence of a competent barrier is correlated ultrastructurally with the formation of the mature-appearing internal membrane contents within epidermal lamellar bodies and, further, with the organization of secreted lamellar body contents into lamellar bilayer unit structures. As barrier function improved between 20 and $22 \mathrm{~d}$ EGA, the extent to which stratum corneum intercellular domains were completely filled with these unit structures also increased.

Lipid content and composition. To determine whether the emergence of a competent barrier correlates with changes in the quantity and/or composition of stratum corneum lipids, the stratum corneum lipids of fetal rats of various EGA were extracted, weighed, and fractionated. The quantities of extractable

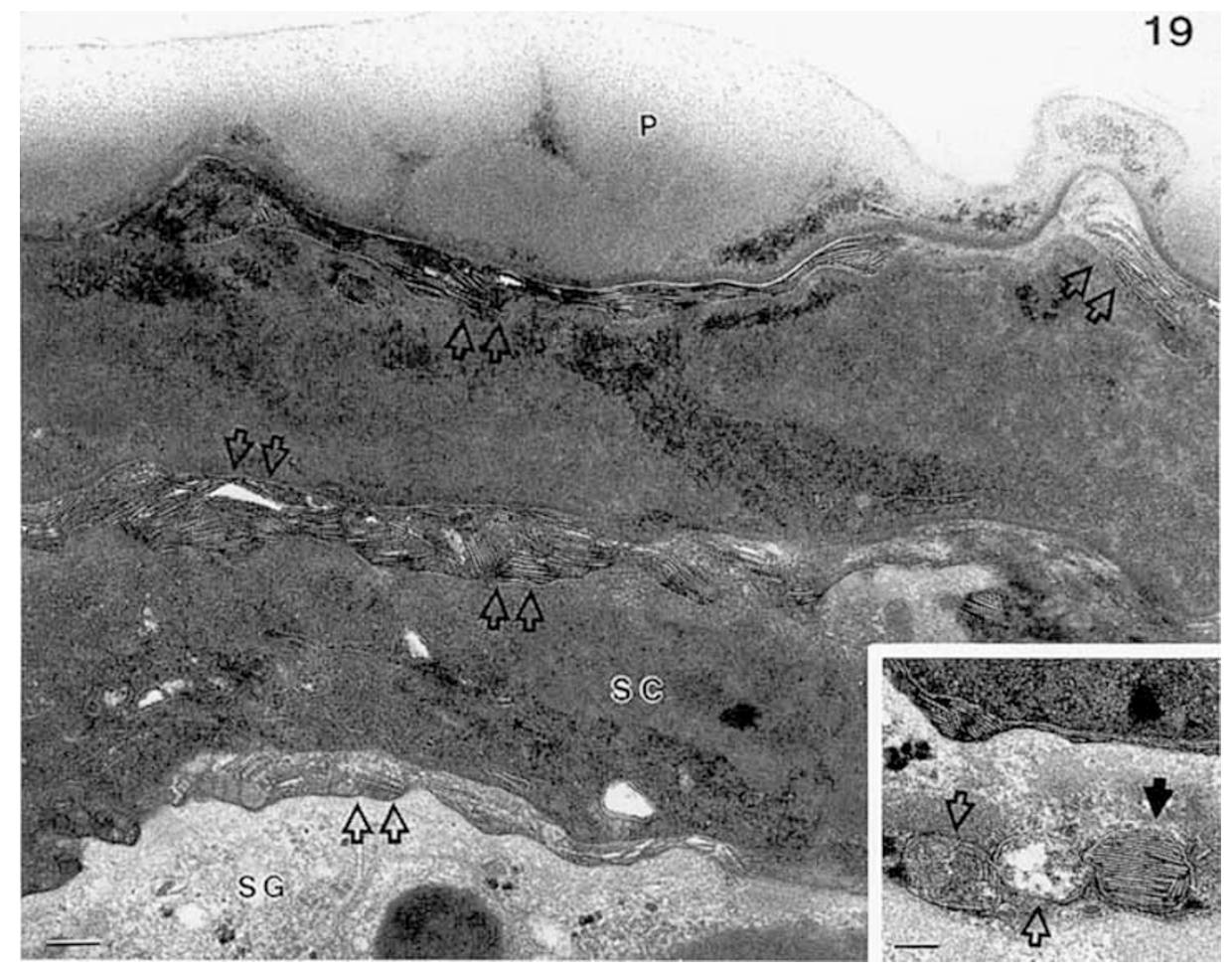

Fig. 6. Electron micrograph of fetal rat epidermis at 19 EGA. The outermost cell layer, the periderm $(P)$, overlies two layers of insipiently cornified, transitional stratum corneum cells $(S C)$. The intercellular domains of these cells contain secreted lamellar body discs that remain unprocessed (double arrows). Also note "clefts" or phase separations within the lamellar contents. Inset shows three lamellar bodies within the stratum granulosum. Some exhibit the typical disc-pattern morphology (solid arrow), whereas others appear to be empty or incompletely formed (open arrows). $\mathrm{Bar}=0.1 \mu \mathrm{m}$. 

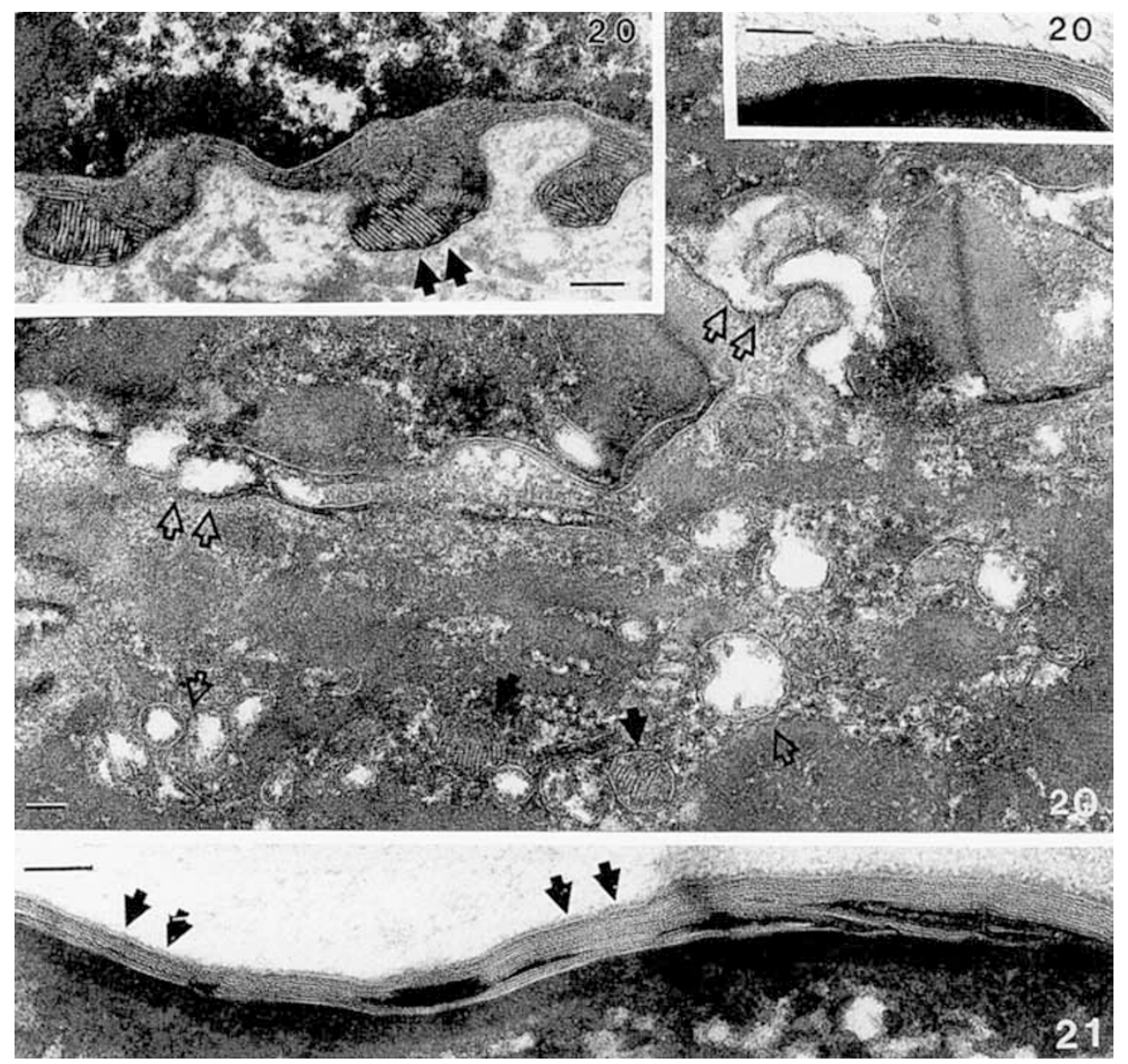

Fig. 7. Electron micrographs of fetal rat epidermis at 20 and $21 \mathrm{~d}$ EGA. The stratum corneum-stratum granulosum interface of a $20-\mathrm{d}$ EGA rat is illustrated in the upper left inset. Note uniform filling of intercellular domain with secreted lamellar material. No clefts or phase separations were evident. In local areas of outer stratum corneum domains, these materials were reorganized to form basic bilayer lamellar unit structures (upper right inset). In the stratum granulosum of 20-d pups, a mixture of well-formed (closed arrows) and incompletely formed (open arrows) lamellar bodies are still seen (middle panel). By $21 \mathrm{~d}$, the stratum corneum intercellular domains show extensive arrays of basic lamellar bilayer units (lower panel) $($ closed arrows). Bar $=0.1 \mu \mathrm{m}$.

lipid increased dramatically in late gestation (Fig. 9). Between 19 $(n=7)$ and $20(n=9) \mathrm{d}$ EGA, there was an increase from 34.08 \pm 4.64 to $50.08 \pm 3.85 \mu \mathrm{g} \mathrm{lipid} / \mathrm{cm}^{2}$, respectively (mean \pm SEM) $(p<0.02)$. There was a further increase in lipid content between 20 and $21(n=7)$ d EGA $\left(74.49 \pm 3.39 \mu \mathrm{g}\right.$ lipid $\left./ \mathrm{cm}^{2}\right)(p<$ $0.001)$, but not between 21 and $22(n=7) \mathrm{d} \mathrm{EGA}$, and a further increase in term pups after 1 postnatal $\mathrm{d}(n=6)(97.72 \pm 7.36$ $\mu \mathrm{g}$ lipid $\left./ \mathrm{cm}^{2}\right)(p<0.05)$. Figure 10 illustrates the inverse relationship between lipid content and TEWL. Pups with a stratum corneum lipid content in excess of $\sim 55 \mu \mathrm{g} \mathrm{lipid} / \mathrm{cm}^{2}$ uniformly exhibited a tight barrier to water loss (TEWL $<0.75 \mathrm{mg} / \mathrm{cm}^{2}$ / $\mathrm{h}$ ), whereas those with a stratum corneum lipid content of $<35$ $\mu \mathrm{g}$ lipid $/ \mathrm{cm}^{2}$ exhibited no measurable barrier function. These results demonstrate that development of a competent barrier correlates with increasing lipid content of the stratum corneum.

To determine whether changes in distribution of specific lipid fractions also occur during late gestation, sphingolipid, neutral lipids, and polar lipids of stratum corneum lipid extracts were fractionated by high-performance TLC scanning densitometry (Figs. 1, 2, 11, and 12). Five fractions were observed within the ceramide region and designated in order of increasing polarity (Fig. 2). The quantity of the two least-polar ceramide fractions (ceramides 1 and 2) increased 6- to 7-fold between 19 d EGA and term (Fig. 11). These two species were also quantitatively the predominant ceramide fractions (data not shown). The most nonpolar ceramide of mammalian stratum corneum has been identified in other TLC systems as the acylceramide $(32-37,42)$. In contrast, the more polar ceramide fractions (ceramides 4 and 5) remained relatively constant (Fig. 11). None of the fetal stratum corneum samples contained quantifiable amounts of glycosphingolipids (Fig. 2). This finding is similar to mature stratum corneum in which lamellar body-derived glycosphingolipids are presumed to be processed to ceramides upon secretion and glycosphingolipids are encountered only in trace quantities $(27,29,30)$.

Among the neutral lipids, the most striking change was a 4fold increase in the cholesterol content of stratum corneum between 19 and 21 d EGA (Fig. 12). Moreover, 7-dehydrocholesterol content also increased $\sim 3$-fold over this time period (data not shown). No change in stratum corneum fatty acid content during fetal development was noted, whereas triacylglycerols increased $\sim 2$-fold, and sterol esters, lipids predominantly of sebaceous gland derivation (47), also increased nearly 3 -fold between 19 and $21 \mathrm{~d}$ EGA and increased a further 2-fold between 21 and $22 \mathrm{~d}$ EGA. The latter increase in sterol ester content may presage the eruption of the pelage, which takes place within a few days after birth. An unidentified nonpolar lipid fraction migrating just in front of the triglyceride standard (triolein) (Fig. 1 , solid arrow) also appears to increase just before term (Fig. 1, lanes 1 and $2=21 \mathrm{~d}$; lanes 3 and $4=\mathrm{d} 22$ ).

Phospholipids were found to be a minor component of all perinatal rat stratum corneum lipid extracts (data not shown), a result that mirrors mature stratum corneum, in which phospholipids provide a minor contribution to stratum corneum lipids $(26-31)$. In fact, only sphingomyelin and phosphatidylethanolamine were identified in quantifiable amounts in our samples, with both of these species increasing between 19 and $21 \mathrm{~d}$ EGA (data not shown). These studies demonstrate that although over- 


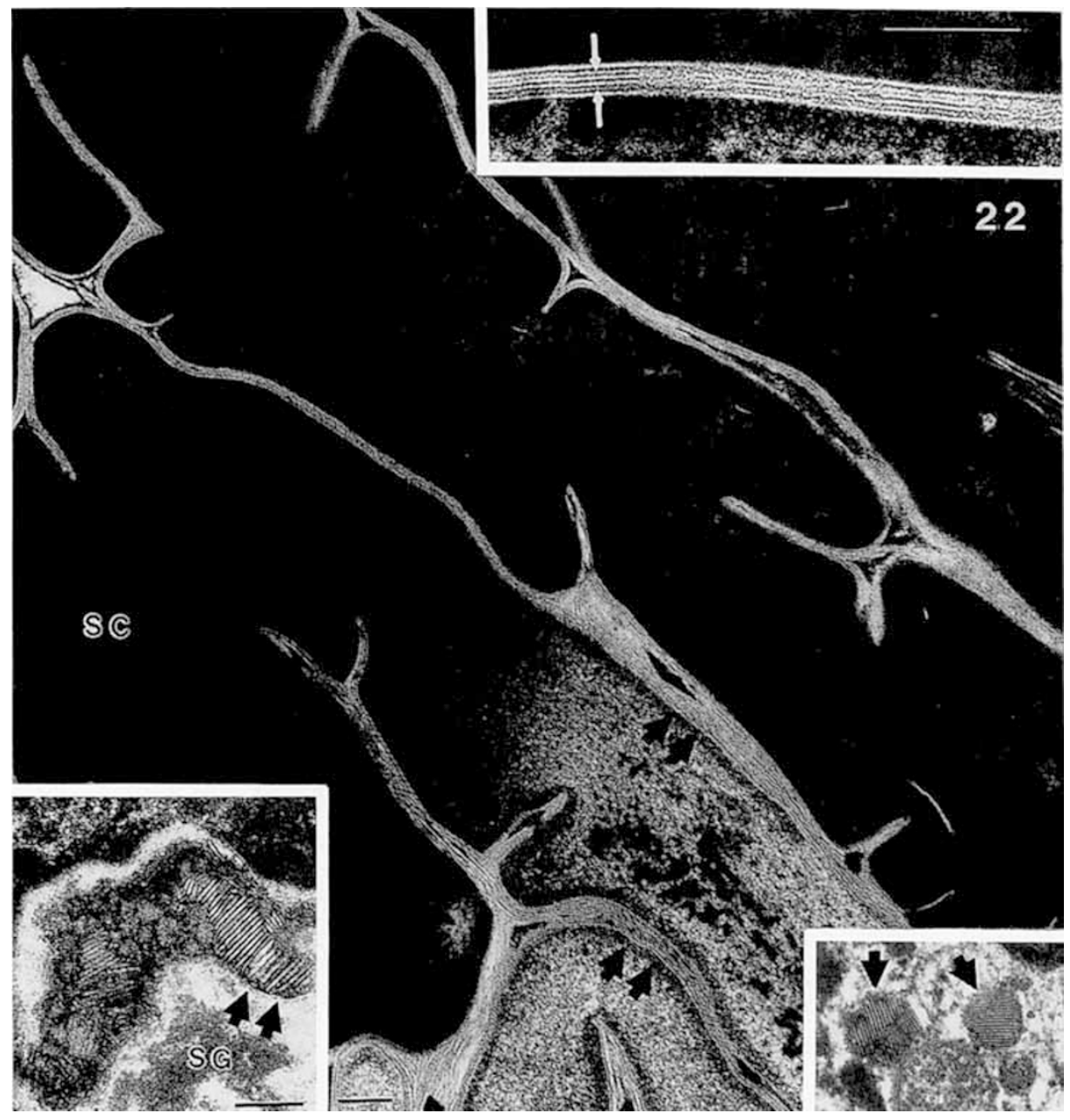

Fig. 8. Electron micrographs of fetal rat epidermis at term ( $22 \mathrm{~d} \mathrm{EGA).} \mathrm{By} \mathrm{term,} \mathrm{stratum} \mathrm{corneum} \mathrm{basic} \mathrm{lamellar} \mathrm{bilayer} \mathrm{units} \mathrm{(enlarged} \mathrm{in} \mathrm{upper}$ right inset) fill the entire stratum corneum interstices, although focal lacunae can occasionally be found (center panel). At this time, most lamellar bodies are well formed (lower right inset). Lower left inset illustrates stratum corneum-stratum granulosum $(S G)$ interface. Note secreted lamellar body contents in intercellular domain (arrows). Bar $=0.1 \mu \mathrm{m}$.

all stratum corneum lipid content increases $\sim 2$-fold between 19 and $21 \mathrm{~d}$ EGA as a competent barrier is established, the content of certain lipid fractions, particularly sterols and nonpolar ceramides, increases even more dramatically.

\section{DISCUSSION}

These studies demonstrate that the epidermal barrier to water loss in the rat is rapidly established during late gestation. Indeed, events occurring during the 20th d of gestation lead to establishment of the permeability barrier, because pups of $19 \mathrm{~d}$ or less EGA displayed no measurable barrier to water loss, whereas by $21 \mathrm{~d}$ the barrier was well established (Fig. 3). A further modest increment in barrier competence was observed at term (22 d) and after the 1 st postnatal day. Stratum corneum was present at $20 \mathrm{~d}$ in our study and others $(48,49)$, but others report its presence by $\mathrm{d} 19(50)$ or $21(51)$. Some differences in interpretation may arise because of cornification of the periderm and the initial appearance of a transitional cell layer before establishment of a typical stratum corneum (52). The cornified cells seen at $19 \mathrm{~d}$ in our study resembled transitional cells in their ultrastructure.

Stern et al. (48) noted that lamellar bodies appear on d 18 in the fetal rat. Day-19 skin was the earliest fetal skin that we examined ultrastructurally. At this time, lamellar bodies were abundant but often appeared to be "empty," i.e. they lacked the typical lamellar substructure. Empty lamellar bodies were not common after $20 \mathrm{~d}$ EGA in our study. It is of interest that similarly abnormal lamellar bodies are abundant in rodents deficient in essential fatty acids (53). Wertz and Downing (54) have reported that the linoleic acid content of neonatal murine epidermal acylglucosylceramides is much lower than that in adult animals ( 13 versus $47 \%$, respectively), and they have proposed that the linoleate-enriched acylglucosylceramide is responsible for the lamellar substructure of these organelles (37). Because we examined only stratum corneum lipids, which do not contain appreciable quantities of glycosphingolipids, our studies do not directly address this issue. However, we did observe lesser quantities of the most nonpolar ceramide (ceramide 1; Fig. 11), which represents the deglycosylated metabolite of the acylglucosylceramide, at stages of development where lamellar body structure was frequently abnormal. Whether the alterations in lamellar body substructure in immature fetal rat epidermis can be attributed solely to deficient linoleic acid content of the acylglucosylceramide or whether more global differences in lamellar body lipid composition underlie these alterations requires further study.

Integumentary lipids in most terrestrial species provide the permeability barrier to water loss (reviewed in 17,55 ). In the mammalian species that have been studied to date, remarkably similar patterns of lipid content and membrane organization have been observed in which neutral lipids (predominantly free sterols and FFA) and ceramides, containing very long chain hydrocarbon groups (C30-C34) and linoleic acid (C18:2), are 


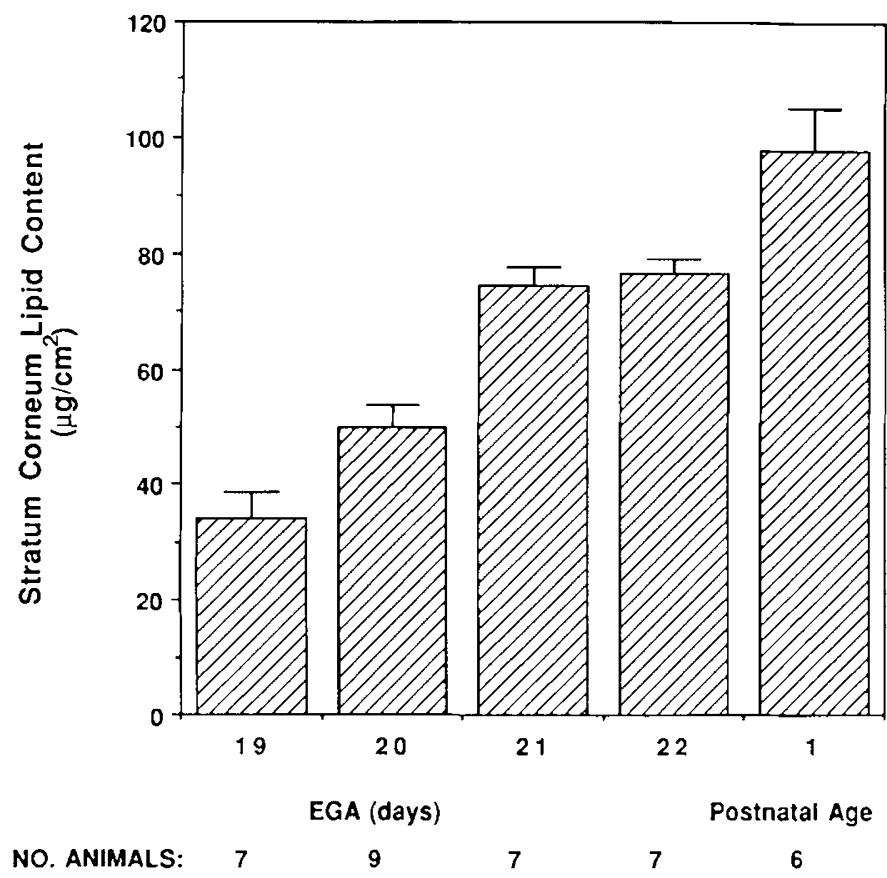

Fig. 9. Lipid content of perinatal rat stratum corneum in relation to gestational age. Stratum corneum sheets were isolated from epidermis and lipids extracted and aliquots weighed (see Materials and Methods). Data are expressed as $\mu \mathrm{g} \mathrm{lipid} / \mathrm{cm}^{2}$ stratum corneum sheet, mean \pm SEM. Significant increments in lipid content occurred between 19 and 20 d EGA $(p<0.02)$, between 20 and 21 d EGA $(p<0.001)$, and between $22 \mathrm{~d}$ EGA (term) and $1 \mathrm{~d}$ postnatal age $(p<0.05)$.

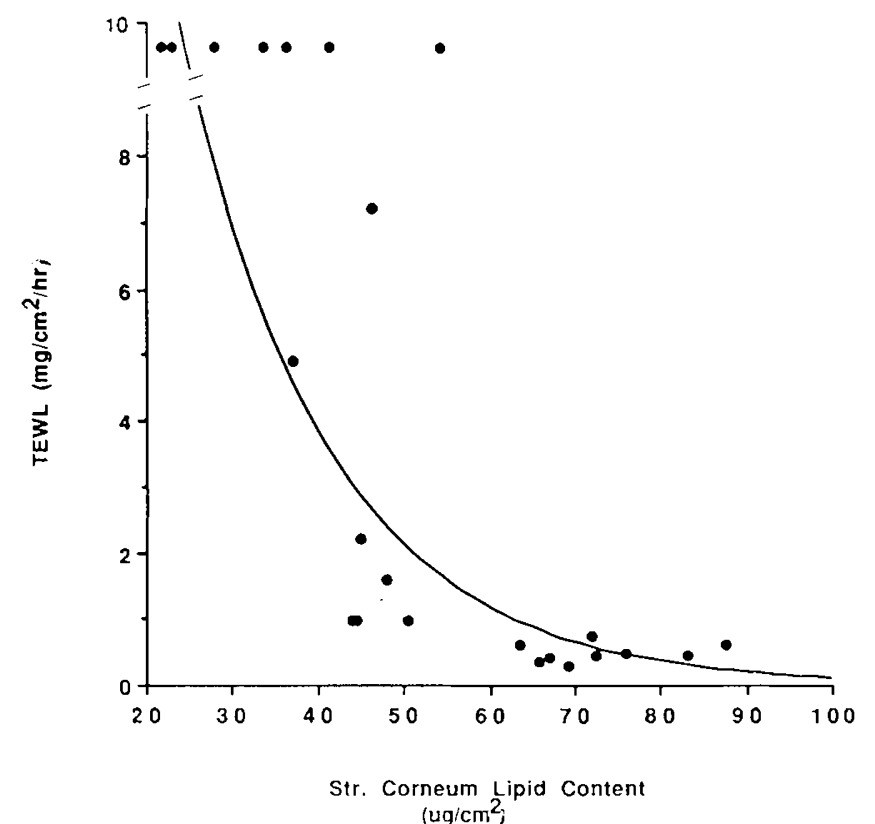

Fig. 10. Transepidermal water loss in relation to stratum corneum lipid contents (See legends to Figs. 1 and 8). A stratum corneum lipid content of $>55 \mu \mathrm{g} / \mathrm{cm}^{2}$ correlated with a competent barrier (TEWL < $0.75 \mathrm{mg} / \mathrm{cm}^{2} / \mathrm{h}$ ), whereas pups having $<35 \mu \mathrm{g}$ lipid $/ \mathrm{cm}^{2}$ exhibited no measurable barrier function.

arranged into multiple membrane bilayers within the intercellular domains of the stratum corneum. Visualization of crosssectional images of stratum corneum intercellular domains has only been possible since the introduction of ruthenium-tetroxide postfixation (18-20). Therefore, previous ultrastructural studies of fetal skin using osmium postfixation would not provide detailed information regarding the structure of these membranes.

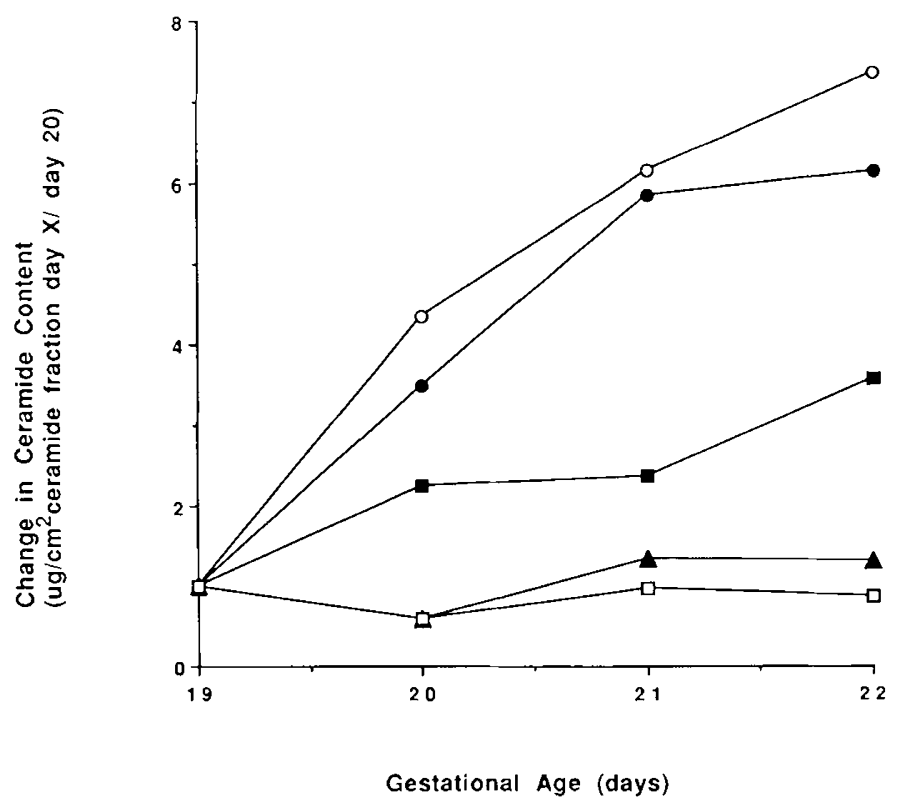

Fig. 11. Ceramide content of fetal rat stratum corneum. Fetal rat stratum corneum ceramides were quantitated by high-performance TLC scanning densitometry (See legends to Figs. 1 and 9 and Materials and Methods). Each data point represents the mean of two fetal samples; data are expressed as the change in ceramide content relative to $\mathrm{d} 19(\mu \mathrm{g}$ ceramide fraction $/ \mathrm{cm}^{2} \mathrm{~d} \mathrm{X} / \mathrm{d} \mathrm{19}$, where $\mathrm{d} X=\mathrm{d} \mathrm{19}, 20,21$, or 22). Ceramides are designated by increasing polarity in this TLC system (Fig. 1): ceramide 1 (solid circles); ceramide 2 (open circles); ceramide 3 (solid squares); ceramide 4 (open squares); and ceramide 5 (solid triangles). The quantity of the most nonpolar ceramides (ceramides 1-3) increased three to seven times between $19 \mathrm{~d} \mathrm{EGA}$ and term $(22 \mathrm{~d})$ in parallel with the emergence of a competent barrier, whereas the most polar ceramides (ceramides 4 and 5) remained relatively constant.

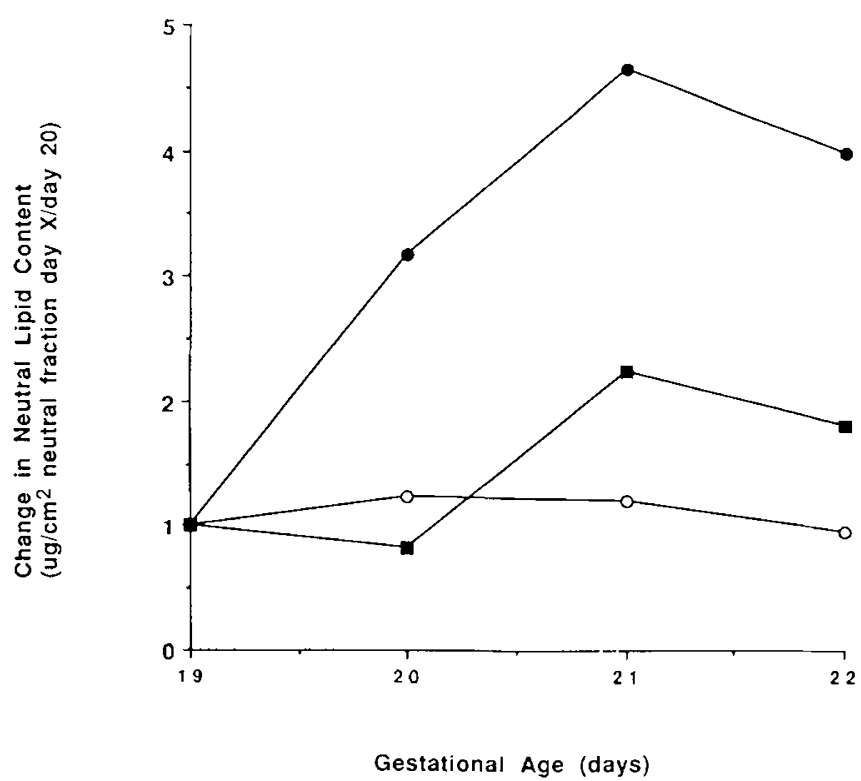

Fig. 12. Neutral lipid content of fetal rat stratum corneum (See legends to Figs. 2 and 9). Each data point represents the mean of two fetal samples; data are expressed as the change in neutral lipid content relative to d 19 ( $\mu$ g neutral lipid fraction $/ \mathrm{cm}^{2} \mathrm{~d} \mathrm{X} / \mathrm{d} 19$, where $\mathrm{d} \mathrm{X}=\mathrm{d}$ $19,20,21$, or 22 ). The quantity of cholesterol (solid circles) increased $\sim 5$-fold during late gestation in the fetal rat, in parallel with the emergence of a competent barrier, whereas the quantity of triglycerides (solid squares) increased $\sim 2$-fold and FFA (open circles) remained relatively constant. 
In the present studies, a competent barrier to water loss in the fetal rat occurred coincident with the organization of stratum corneum lipids into basic lamellar bilayer structures (Figs. 7 and 8 ). Before onset of a functional barrier, abundant lamellar material was evident within the intracellular spaces of the outermost epidermal cell layers, but this material was arranged in arrays of short discs resembling newly secreted lamellar bodies (Fig. 6) rather than into broad continuous lamellar bilayer unit structures. However, a failure to process lamellar body contents after secretion is likely to be too simplistic an interpretation for these observations because stratum corneum of 19-d pups was not enriched in glycosphingolipids or phospholipids as one would predict for unprocessed lamellar body-derived lipids $(23,24)$. Coincident with establishment of a functional barrier, the quantity of lipid per unit area of stratum corneum increased $\sim 2$-fold (Fig. 9), and, in particular, the quantity of free sterols (Fig. 12) and the most nonpolar ceramide species (Fig. 11) increased 4and 6- to 7-fold, respectively.

Stratum corneum lipids also provide the barrier to absorption of epicutaneously applied compounds, and the mature barrier is particularly impermeable to water-soluble compounds. In preterm infants, both TEWL and percutaneous absorption of xenobiotics are increased (3-8). Although we found no barrier to TEWL until late gestation $(20 \mathrm{~d})$ in the fetal rat, it is possible that other measures of permeability barrier function, such as percutaneous absorption of water-soluble materials, may demonstrate some barrier function at earlier stages in development $(56,57)$. Indeed, our ultrastructural studies, which show abundant intercellular lamellar materials within stratum corneum of 19-d pups, would predict some barrier capacity. In many ways, the developing fetal rat barrier is analogous to the dynamic sequence that follows acute, solvent-induced disruption of the barrier in mature rodents (reviewed in 17, 58). The degree of barrier dysfunction is correlated with the quantity of stratum corneum lipid removed (47). Recovery occurs quickly (39), over a time frame comparable to the development of barrier competence in the fetal rat. In the solvent-induced model, an initial secretion of lamellar body contents is followed by a burst in sterol, fatty acid, and sphingolipid synthesis (58), which is followed by the appearance of nascent lamellar bodies and further secretion (17). Lipids reaccumulate in stratum corneum extracellular domains with reappearance of basic lamellar unit structures. This entire process of barrier recovery requires $24-36 \mathrm{~h}$, but is more than $50 \%$ complete by $6 \mathrm{~h}$.

In summary, these studies demonstrate that in the rat, as in man (3-8) and swine (56), development of a competent epidermal barrier to water loss occurs late in gestation. Establishment of a competent barrier in the rat was correlated with 1 ) organization of stratum corneum lipids into basic lamellar unit structures; 2) increasing stratum corneum thickness; 3) increasing stratum corneum lipid content; and 4) enrichment of stratum corneum lipid with cholesterol and nonpolar ceramides. The close temporal correlation between establishment of a functional barrier and changes in the generation, organization, quantity, and distribution of stratum corneum lipids implies that the developmental regulation of these events will be a fruitful area for further study.

Acknowledgments. The authors thank Dennis Tyler, Barbara E. Brown, and Robin Stierwalt for their able technical assistance; Dr. Peter M. Elias for his helpful discussions at many stages of the study; and Bil Chapman and Raymond Pelayo for assistance in preparation of the manuscript.

\section{REFERENCES}

1. Wildnauer RH, Kennedy R 1970 Transepidermal water loss in human newborns. J Invest Dermatol 54:483-486

2. Cunico RL, Maibach HI, Khan H, Bloom E 1977 Skin barrier properties in the newborn transepidermal water loss and carbon dioxide emission rates. Biol Neonate 32:177-182
3. Rutter N, Hull D 1979 Water loss from the skin of term and preterm babies. Arch Dis Child 54:858-868

4. Nachman RL, Esterly NB 1971 Increased skin permeability in preterm infants. J Pediatr 79:628-632

5. Wilson DR, Maibach HI 1980 Transepidermal water loss in vivo. Preterm and term infants. Biol Neonate 37:180-185

6. Hammarlund K, Sedin G 1979 Transepidermal water loss in newborn infants. III. Relation to gestational age. Acta Paediatr Scand 68:795-801

7. Barker N, Hadgraft J, Rutter N 1987 Skin permeability in the newborn. J Invest Dermatol 88:409-411

8. Harpin VA, Rutter N 1983 Barrier properties of the newborn infant's skin. J Pediatr 102:419-425

9. Hey EN, Katz G 1969 Evaporative water loss in the newborn baby. J Physiol 200:605-619

10. Hamarlund K, Nilsson GE, Oberg PA, Sedin G 1977 Transepidermal water loss in newborn infants. I. Relation to ambient humidity and site of measurement and estimation of total transepidermal water loss. Acta Paediatr Scand 66:553-562

11. Wu PYU, Hodgman JE 1974 Insensible water loss in pretenn infants: changes with postnatal development and non-ionizing radiant energy. Pediatrics 54:704-712

12. Lorenz JM, Kleinman LI, Kotagal UR, Reller MD 1982 Water balance in very low birth weight infants: relationship to water and sodium intake and effect on outcome. J Pediatr 101:423-432

13. Baumgart S, Engle WD, Fox WW, Polin RA 1981 Radiant warmer power and body size as determinants of insensible water loss in the critically ill neonate. Pediatr Res 15:1495-1499

4. Maurer A, Micheli JL, Schuetz Y, Fregmond D, Jequier E 1984 Transepidermal water loss and resting energy expenditure in preterm infants. Helv Paediatr Acta 39:405-418

15. Belgaumkar JK, Scott KE 1975 Effects of low humidity on small premature infants in servocontrol incubators. I. Decrease in rectal temperature. Biol Neonate 26:337-347

16. Evans NJ, Rutter N 1986 Development of the epidermis in the newborn. Biol Neonate 49:74-80

17. Elias PM, Menon GK 1991 Structural and lipid biochemical correlates of the epidermal permeability barrier. Adv Lipid Res 24:1-26

18. Landmann L 1984 The epidermal permeability barrier. Comparison between in vivo and in vitro lipid structures. Eur J Cell Biol 33:258-264

19. Madison KC, Swartzendruber DC, Wertz PW, Downing DT 1987 Presence of intact intercellular lipid lamellae in the upper layers of the stratum corneum. J Invest Dermatol 88:714-718

20. Hou SYE, Mitra AK, White SH, Menon GK, Ghadially R, Elias PM 1991 Membrane structures in normal and essential fatty acid deficient stratum corneum: characterization by ruthenium tetroxide staining and $\mathrm{x}$-ray diffraction. J Invest Dermatol 96:215-223

1. Wolff-Schreiner E 1977 Ultrastructural cytochemistry of the epidermis. Int J Dermatol 16:77-102

22. Grayson S, Johnson-Winegar AG, Elias PM 1983 Isolation of lamellar bodies from neonatal mouse epidermis by elective sequential filtration. Science 221:962-964

23. Grayson S, Johnson-Winegar AG, Wintroub BU, Epstein Jr EH, Elias PM 1985 Lamellar body enriched fractions from neonatal mice. Preparative techniques and partial characterization. J Invest Dermatol 85:289-295

24. Freinkel RF, Traczyk TN 1985 Lipid composition and hydrolase content of lamellar granules of fetal rat epidermis. J Invest Dermatol 85:295-298

25. Menon GK, Grayson S, Elias PM 1986 Cytochemical and biochemical localization of lipase and sphingomyelinase activity in mammalian epidermis. $\mathrm{J}$ Invest Dermatol 86:591-597

26. Long VJW 1970 Variations in lipid composition at different depth in cow snout epidermis. Br J Dermatol 55:267-273

27. Gray GM, Yardley HJ 1975 Different populations of pig epidermal cells: isolation and lipid composition. J Lipid Res 16:441-447

28. Elias PM, Goerke J, Friend DS 1977 Mammalian epidermal barrier layer lipids: composition and influence on structure. I Invest Dermatol 69.535546

29. Cox P, Squier CA 1986 Variations in lipids in different layers of porcine epidermis. J Invest Dermatol 87:741-744

30. Lampe MA, Williams ML, Elias PM 1983 Human epidermal lipids: characterization and modulation during differentiation. J Lipid Res 24:131-140

31. Lampe MA, Burlingame AL, Whitney JA, Williams ML, Brown BE, Roitman E, Elias PM 1983 Human stratum corneum lipids: characterization and regional variation. J Lipid Res 24:120-130

32. Ansari MNA, Nicolaidies N, Fu HC 1970 Fatty acid composition of the living layer and stratum corneum lipids of human sole skin epidermis. Lipids 5:838-845

33. Gray GM, White RJ 1978 Glycosphingolipids and ceramides in human and pig epidermis. J Invest Dermatol 70:336-341

34. Wertz PW, Downing DT 1983 Ceramides of pig epidermis: structure determination. J Lipid Res 24:759-765

35. Gray GM, White RJ, Majer FR 1978 1-(3'-O-acyl)-B-glucosyl-N-dihydroxypentatriacontadienoylsphingosine, a major component of the glucosylceramides of pig and human epidermis. Biochim Biophys Acta 528:127-137

36. Bowser PA, Nugteren DH, White RJ, Houtsmuller VMT, Protley C 1985 Identification, isolation and characterization of epidermal lipids containing linoleic acid. Biochim Biophys Acta 834:419-428

37. Wertz PW, Downing DT 1982 Glycolipids in mammalian epidermis: structure 
and function in the water barrier. Science 217:1261-1262

38. Grubauer G, Feingold KR, Elias PM 1987 Relationship of epidermal lipogenesis to cutaneous barrier function. J Lipid Res 28:746-752

39. Menon GK. Feingold KR, Moser AH, Brown BE, Elias PM 1985 De novo sterologenesis in the skin. II: regulation by cutaneous barrier requirements. J Lipid Res 26:418-427

40. Feingold KR, Mao-Quiang M, Proksh E, Menon GK, Brown BE, Elias PM 1991 The lovastatin-treated rodent: a new model of barrier disruption and epidermal hyperplasia. J Invest Dermatol 96:201-209

41. Bligh EG, Dyer WJ 1959 A rapid method of total lipid extraction and purification. Can J Biochem Physiol 37:911-917

42. Ponec M, Weerheim A, Kempenaar J, Mommaas AM, Nugteren DH 1988 Lipid composition of cultured human keratinocytes in relation to their differentiation. J Lipid Res 29:949-961

43. Gaylor JL, Sault FM 1961 Localization and biosynthesis of 7-dehydrocholesterol in rat skin. $J$ Lipid Res 5:422-431

44. Elias PM, Williams ML, Maloney ME, Fritsch PO, Chung J-C 1987 Druginduced animal models of ichthyosis. In: Maibach HI. Lowe NJ (eds) Dermatopharmacology and Dermatotoxicology. Karger, Basel, Switzerland, pp $105-126$

45. Fowler SD, Greenspan PH 1985 Application of nile red, a fluorescent hydrophobic probe, for the detection of neutral lipid deposits in tissue sections. J Histochem Cytochem 33:833-836

46. McNutt NS, Crain MS 1981 Quantitative electron microscopic comparison of lymphatic contents in mycosis fungoids and in benign infiltrates in the skin. Cancer 47:163-166

47. Grubauer G, Feingold KR, Harris RM, Elias PM 1989 Lipid content and lipid type as determinants of the epidermal permeability barrier. J Lipid Res
30:89-96

48. Stern IB, Dayton L, Duecy J 1971 The uptake of tritiated thymidine by the dorsal epidermis of the fetal and newborn rat. Anat Rec 170:225-234

49. Bauer FW 1972 Differentiation and keratinization of fetal rat skin. II. Ultrastructural study of the epidermis in vivo and in vitro. Dermatologica 145:1636

50. Hanson $J 1947$ The histogenesis of the epidermis in the rat and mouse. $J$ Anat 81:174-197

51. Buxman MM, Kocarnik MJ, Holbrook KA 1979 Differentiation markers in fetal epidermis: transglutaminase and transpeptidase. J Invest Dermatol $72: 171-177$

52. Schwartz J, Stern IB 1980 Interrelationships between cornification and cell migration of fetal rat epidermis in vitro. J Anat 131:471-480

53. Elias PM, Brown BE 1978 The mammalian cutaneous permeability barrier: defective barrier function in essential fatty acid deficiency correlates with abnormal intercellular lipid deposition. Lab Invest 39:574-583

54. Wertz PW, Downing DT 1986 Linoleate content of epidermal acylglucosylceramide in newborn, growing and mature mice. Biochim. Biophys Acta 876:469-473

55. Hadley NJ 1989 Lipid water barriers in biological systems. Prog Lipid Res 28:1-33

56. Kurihara-Bergstrom T, Good WR, Signor C, Woodwroth M 1990 Epidermal differentiation and permeability in fetal pig skin. Pharmacol Res 7:12011204

57. Tregear RT 1966 Molecular movement: the permeability of skin. In: Physical Functions of the Skin. Academic Press, New York, pp 1-52

58. Feingold KR 1991 The regulation and role of epidermal lipid synthesis. Adv Lipid Res 24:57-82 